\title{
Expression and clinical significance of methyl-CpG binding domain protein 2 in high-grade serous ovarian cancer
}

\author{
WANGANG GONG ${ }^{1-4}$, MAOWEI NI ${ }^{2-4}, \mathrm{ZHONGBO} \mathrm{CHEN}^{2-4}$ and $\mathrm{ZHIGUO} \mathrm{ZHENG}^{2-4}$ \\ ${ }^{1}$ College of Life Sciences, Zhejiang Chinese Medical University, Hangzhou, Zhejiang 310053; ${ }^{2}$ Institute of Cancer and Basic \\ Medicine, Chinese Academy of Sciences; ${ }^{3}$ Zhejiang Cancer Research Institute, Cancer Hospital of The University of Chinese \\ Academy of Sciences; ${ }^{4}$ Zhejiang Cancer Research Institute, Zhejiang Cancer Hospital, Hangzhou, Zhejiang 310022, P.R. China
}

Received February 6, 2020; Accepted June 8, 2020

DOI: $10.3892 / \mathrm{ol} .2020 .11836$

\begin{abstract}
Platinum resistance is an important cause of clinical recurrence and mortality of patients with high-grade serous ovarian cancer (HGSOC). Methyl-CpG binding domain protein 2 (MBD2) serves an important role in tumor progression; however, its role in HGSOC remains unclear. The aim of the present study was to investigate the expression of MBD2 in HGSOC and its role in drug resistance and prognosis of HGSOC. MBD2 expression was analyzed by immunohistochemical staining and western blotting. The associations between MBD2 expression and clinical pathological features, platinum resistance and patient prognosis were analyzed using a $\chi^{2}$ test, Kaplan-Meier analysis and Cox regression analysis. Positive MBD2 expression was detected in 73 (63.5\%) of the HGSOC tissue samples, whereas it was undetectable in all 16 normal tissue samples (100\%) analyzed, indicating a significantly higher expression level in tumor tissues compared with normal tissues $(\mathrm{P}<0.001)$. Additionally, MBD2 expression was significantly higher in platinum-resistant cases compared with that in platinum-sensitive cases $(\mathrm{P}<0.05)$. In addition, high expression of MBD2 was negatively associated with relapse-free survival $(\mathrm{P}<0.05)$. In conclusion, $\mathrm{MBD} 2$ was demonstrated to be a potential drug target and a biomarker for poor prognosis in HGSOC.
\end{abstract}

\section{Introduction}

Ovarian cancer is the deadliest type of malignant tumor in gynecology, and it seriously affects the lives of women (1). In $2018,152,000$ women died from ovarian cancer worldwide, and the overall 5-year survival rate was $\sim 30 \%(2,3)$. High-grade serous ovarian cancer (HGSOC) is the most common form

Correspondence to: Dr Zhiguo Zheng, Zhejiang Cancer Research Institute, Zhejiang Cancer Hospital, 1 Banshan Road, Hangzhou, Zhejiang 310022, P.R. China

E-mail: zhengzg@zjcc.org.cn

Key words: high-grade serous ovarian cancer, methyl-CpG binding domain protein 2 , drug resistance, relapse of ovarian cancer, as well as the most deadly and invasive subtype (4). The standard treatment for HGSOC is cytoreductive surgery combined with platinum and paclitaxel-based chemotherapy (4). Although patients are initially sensitive to chemotherapy, the majority eventually develop drug resistance, which is associated with increased mortality (5). Thus, the identification of targets to treat HGSOC resistance and prognostic biomarkers is of great significance for the treatment of HGSOC.

Hypermethylation of $\mathrm{CpG}$ islands in the gene promoter region causes gene silencing and is an important characteristic of cancer cells (6). Methyl-CpG binding domain proteins (MBDs) silence gene expression by binding to methylated DNA and interacting with histone deacetylases (HDACs) and histone methyltransferases, thus affecting carcinogenesis $(7,8)$. The central region of MBD2, a member of the MBD family, contains two binding domains, MBD and a transcriptional inhibition domain, which are responsible for methylation specific binding and transcriptional inhibition (9). MBD2 usually binds to methylated promoter $\mathrm{CpG}$ islands (clusters of high density $\mathrm{CpG}$ dinucleotides) and acts as a methylation-dependent transcriptional repressor (10). MBD2 can recruit the nucleosome remodeling and deacetylase/Mi-2 complex to silence genes through a methylation-related mechanism (11-14). However, one study also reported that MBD2 is a transcriptional activator of the cAMP response promoter (15). These controversial results suggest that MBD2 serves different roles according to the cell type. Increasing evidence indicates that MBD2 is associated with the occurrence and development of a variety of tumors, and its role in different tumors is also different. For example, MBD2 expression is higher in hepatocellular carcinoma (HCC), glioblastoma (GBM) and breast cancer tissues compared with normal tissues (16-18), whereas it is lower in gastric, cervical and colon cancer tissues compared with normal tissues $(17,19,20)$. In addition, high expression of MBD2 is associated with poor prognosis of patients with HCC (21). A previous study demonstrated that stable short hairpin RNA (shRNA)-mediated downregulation of MBD2 inhibits the proliferation of SK-BR-3, MDA-MB-231 and MDA-MB-435 breast cancer cells cultured in vitro (22). However, Yuan et al reported that MBD2 downregulation combined with HDAC-1 promotes the growth and metastasis of colorectal cancer (23). 
To the best of our knowledge, the expression of MBD2 in HGSOC has not been studied to date; thus, the aim of the present study was to investigate the association between MBD2 expression and the prognosis of patients with HGSOC and platinum resistance.

\section{Materials and methods}

Bioinformatics analysis of MBD2 expression in human OC. The Human Protein Atlas (http://www.proteinatlas.org) is a database that provides immunohistochemical (IHC) staining data for common cancers, normal tissues and cell lines; it contains $>10$ million IHC images (24-27). The expression data of MBD2 in different normal tissues can be obtained by entering MBD2 in the Tissue Atlas module, and the results were displayed on the webpage.

Patient selection. The study was approved by the Ethics Committee of Zhejiang Cancer Hospital (approval no. IRB-2015-175) and written informed consent was obtained from all patients. In total, 131 female patients were enrolled onto the present study (age range, 39-74 years old), including 115 HGSOC (age range, 39-74 years old) and 16 normal patients (age range, 39-65 years old). The 131 frozen tissue samples used in this study were provided by the Biobank of Zhejiang Cancer Hospital (Hangzhou, China). All tissue samples were collected in the operating room of the Zhejiang Cancer Hospital (Hangzhou, China) from January 2008 to June 2014. The samples were fixed and paraffin embedded. Among all samples, there were 115 HGSOC tissue samples (including 1 case of stage I, 11 cases of stage II, 95 cases of stage III and 8 cases of stage IV) and 16 normal ovarian tissue samples. Normal ovarian tissues samples were obtained patients with other gynecological benign tumors. The diagnosis and stage of HGSOC are determined by two independent experienced pathologists in the Zhejiang Cancer Hospital (Hangzhou, China). Histological classification and tumor staging were performed according to World Health Organization histological classification criteria and the International Federation of Gynaecology and Obstetrics (FIGO) staging criteria (28).

All patients received standard chemotherapy and were divided into platinum-resistant and platinum-sensitive (including partially sensitive) groups according to the following criteria: i) Platinum-resistant group, patients displaying progression or recurrence $<6$ months after finishing platinum treatment; and ii) platinum-sensitive group, those displaying recurrence $>6$ months after platinum treatment or those who did not exhibit recurrence.

Immunohistochemical staining. The immunohistochemical staining kit was purchased from Beijing Zhongshan Golden Bridge Biotechnology Co., Ltd. The tissue samples were fixed with $10 \%$ formalin at room temperature for $24 \mathrm{~h}$. Paraffin-embedded tissue samples were cut into $4-\mu \mathrm{m}$-thick sections and placed at $72^{\circ} \mathrm{C}$ for $30 \mathrm{~min}$, then dewaxed and hydrated by xylene and ethanol. The sections were dewaxed with xylene twice for $5 \mathrm{~min}$ each time, and the gradient ethanol rehydration (100\% for 3 min twice, $95 \%$ for 3 min twice, $80 \%$ for $3 \mathrm{~min}$ ) was rinsed with clean running water for $30 \mathrm{~min}$. Antigens were retrieved by pressure cooker treatment for $90 \mathrm{sec}$

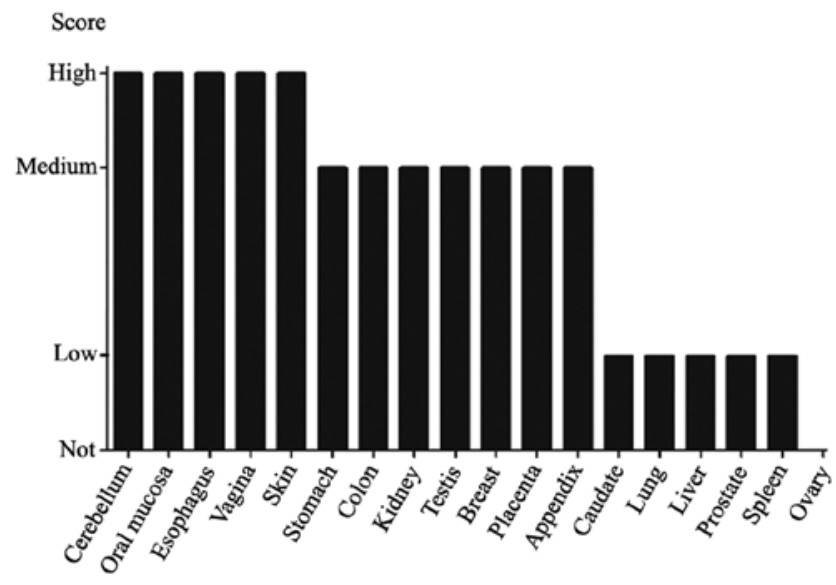

Figure 1. Methyl-CpG binding domain protein 2 is expressed in normal tissues. Image was taken from The Human Protein Atlas (HPA), https://www. proteinatlas.org/ENSG00000134046-MBD2/tissue.

in $0.01 \mathrm{mmol} / 1$ citrate buffer. After three washes, the slides were placed in 3\% hydrogen peroxide solution for 5-10 $\mathrm{min}$, washed with running water twice and phosphate buffer saline (PBS) for $5 \mathrm{~min}$, and incubated with rabbit anti-human MBD2 polyclonal primary antibody (1:100; cat. no. ab188474; Abcam) overnight at $4^{\circ} \mathrm{C}$. After washing with PBS twice for $5 \mathrm{~min}$, slides were incubated with horseradish peroxidase-conjugated rabbit secondary antibodies (cat. no. PV-6000, OriGene Technologies, Inc.) at room temperature for $20 \mathrm{~min}$, followed by washing and 3,3'-diaminobenzidine staining at room temperature for $2 \mathrm{~min}$. The sections were counterstained with haematoxylin for $1 \mathrm{~min}$ at room temperature and washed with running water three times. This was followed by incubation with $1 \%$ hydrochloric acid alcohol for $1 \mathrm{~min}$ and dehydration with a gradient of ethanol ( $80 \%$ for $10 \mathrm{sec}, 95 \%$ for $10 \mathrm{sec}$, $100 \%$ for $5 \mathrm{~min}$ three times), and treated with xylene for $3 \mathrm{~min}$ at room temperature. Images were captured using a BX63 fluorescence microscope with a CCD camera (DP80; Olympus Corporation) at 200x magnification.

Evaluation of immunohistochemical staining. The expression of MBD2 detected by immunohistochemistry was evaluated by calculating the sum of staining intensity and the proportion of positively-stained cells, as previously described (29). Briefly, according to the staining intensity, there were four levels, including negative ( 0 point), weak positive ( 1 point), intermediate positive ( 2 points) and strong positive ( 3 points). The proportion of positively-stained cells was scored as follows: $<5 \%, 0$ point; $5-25 \%, 1$ point; $26-50 \%, 2$ points; $51-75 \%, 3$ points; and $>75 \%, 4$ points. Finally, the sum of the percentage of positive cells score and the intensity score was calculated to provide the final score of MBD2 expression, which ranged between 0 and 7. A final score of 0 points indicated no expression, 1-4 points indicated low expression, and 5-7 points indicated high expression.

Western blotting. Western blotting was performed as previously described (17). Tissues were lysed in ice-cold cell lysis buffer (Beyotime Institute of Biotechnology) containing protease inhibitors (Thermo Fisher Scientific, Inc.), and the protein concentration in tissue extracts was quantified using 

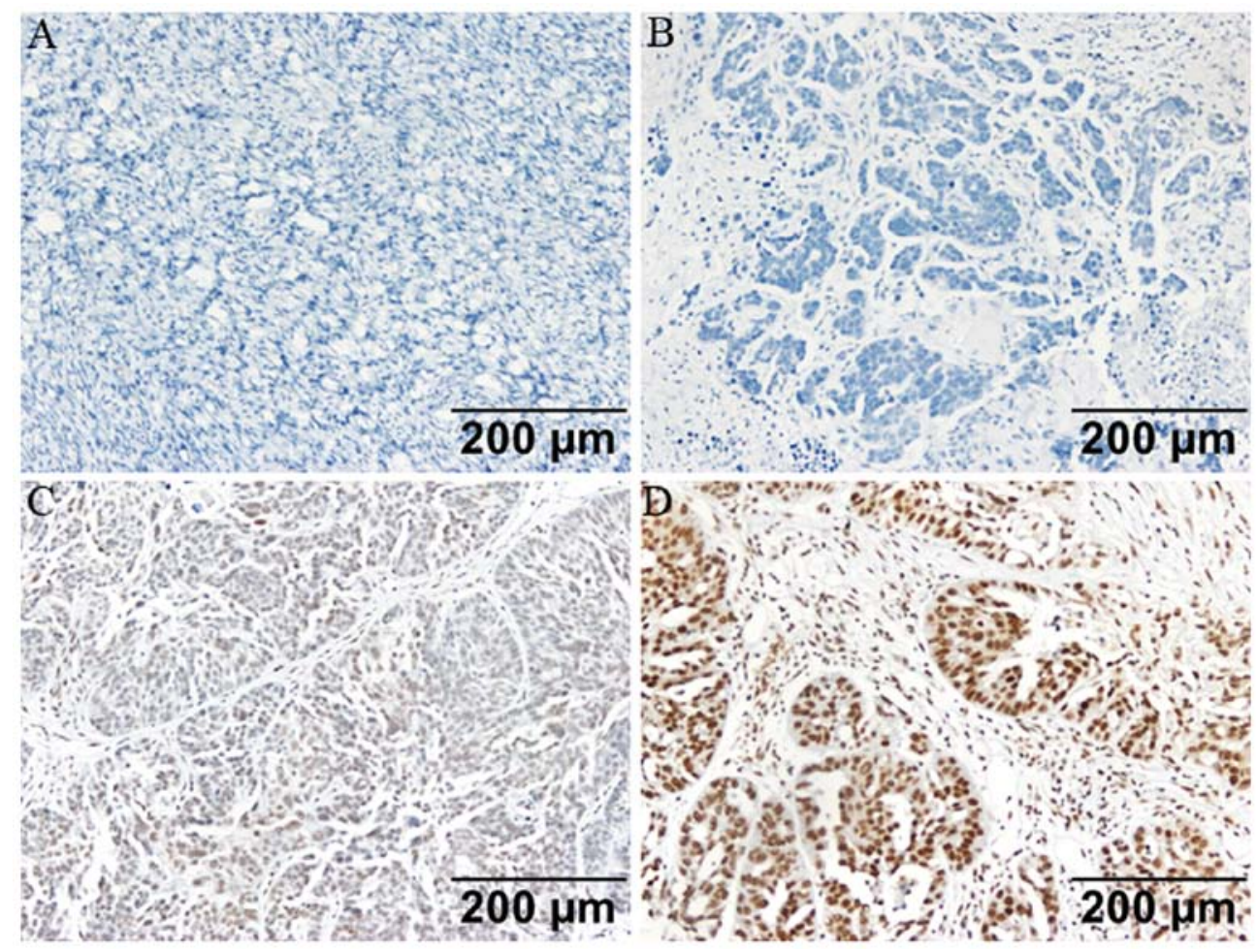

Figure 2. Detection of MBD2 by immunohistochemistry. Negative expression of MBD2 in (A) normal ovarian tissues and (B) HGSOC tissues. (C) Low expression of MBD2 in HGSOC tissues. (D) High expression of MBD2 in HGSOC tissues. MBD2, methyl-CpG binding domain protein 2; HGSOC, high-grade serous ovarian cancer.

the bicinchoninic acid protein assay kit (Beyotime Institute of Biotechnology). Equal amounts of protein $(25 \mu \mathrm{g} / \mathrm{lane})$ from each extract were denatured and separated using a $10 \%$ polyacrylamide gel (Beyotime Institute of Biotechnology), and then transferred by electrophoresis onto a nitrocellulose membrane (Thermo Fisher Scientific, Inc.). The membranes were blocked with 5\% non-fat dried milk in PBST for $1 \mathrm{~h}$ at room temperature and incubated with primary antibodies against MBD2 (1:1,000; cat. no. ab188474; Abcam) and $\beta$-actin (1:3,000; cat. no. EM21002; Hangzhou Huaan Biological Technology, Ltd.) at $4^{\circ} \mathrm{C}$ overnight. Membranes were then incubated with horseradish peroxidase-conjugated anti-mouse (1:3,000; cat. no. 170-6516; Bio-Rad Laboratories, Inc.). or anti-rabbit secondary antibodies (1:3,000; cat. no. 170-6515; Bio-Rad Laboratories, Inc.). The membranes were developed using SuperSignal West Pico Substrate and CL-XPosure Film (Thermo Fisher Scientific, Inc.). Western blot results were analyzed using Image Lab 3.0 (Bio-Rad Laboratories, Inc.).

Statistical analysis. A Pearson Chi-square $\left(\chi^{2}\right)$ test or Fisher's exact test was used to analyze the associations between MBD2 expression and clinicopathological features, including age, FIGO stage, degree of differentiation, cancer antigen-125 (CA-125), lymph node metastasis and postoperative residual disease size. The associations between platinum resistance and MBD2 expression, as well as clinical features were analyzed using $\chi^{2}$ test or Fisher's exact test and multiple logistic regression. The relapse date was defined as the time when new lesions were indentified by radiographic analysis in patients with HGSOC after the completion of surgery, so as to calculate the relapse-free survival (RFS) from the date of surgical resection to the date of relapse. The Kaplan-Meier method was also used, and Cox proportional hazard regression, log-rank test and Breslow test were used for univariate and multivariate survival analyses of RFS. The unpaired Student's t-test or Fisher's exact test was used to compare the mean of two groups. Analyses were performed using SPSS version 18.0 (SPSS, Inc.). $\mathrm{P}<0.05$ was considered to indicate a statistically significant difference.

\section{Results}

MBD2 expression and clinicopathological characteristics of patients with HGSOC. A query from The Human Protein Atlas database demonstrated that MBD2 was not expressed in normal ovarian tissues (Fig. 1). The expression of MBD2 in 115 HGSOC tissue samples and 16 normal ovarian tissue samples from the patients with normal ovariectomy was investigated by immunohistochemistry (Fig. 2). The results demonstrated that MBD2 was expressed in 73 HGSOC samples (63.5\%), but not expressed in 42 HGSOC samples (36.5\%). No MBD2 expression was detected in all 16 normal ovarian tissue samples $(100 \%)$. Fisher's exact test demonstrated that the expression of MBD2 in HGSOC tissues was significantly higher compared with that in normal ovarian tissues $(\mathrm{P}<0.001$, Table I). In addition, among the 115 HGSOC samples, there was no significant association between MBD2 expression and age, FIGO stage, histological grade, CA-125, lymph node metastasis or postoperative residual tumor size $(\mathrm{P}>0.05)$, whereas MBD2 expression was significantly associated with platinum resistance $(\mathrm{P}=0.001$; Table $\mathrm{II})$. The expression of MBD2 was also detected by western blotting in eight HGSOC tissues and 
Table I. Expression of methyl-CpG binding domain protein 2 in HGSOC and normal ovarian tissue samples.

\begin{tabular}{lccc}
\hline & \multicolumn{3}{c}{ MBD2 expression } \\
\cline { 2 - 4 } Variables & Low & High & P-value \\
\hline HGSOC & 42 & 73 & $<0.001$ \\
Normal & 16 & 0 & \\
\hline
\end{tabular}

Statistical analysis was performed using a Fisher's exact test. HGSOC, high-grade serous ovarian cancer.

Table II. Associations between the expression level of MBD2 and clinicopathological characteristics.

\begin{tabular}{|c|c|c|c|}
\hline \multirow[b]{2}{*}{ Variables } & \multicolumn{3}{|c|}{ MBD2 expression } \\
\hline & Low & High & P-value \\
\hline Age, years & & & $0.157^{\mathrm{a}}$ \\
\hline$\leq 54$ & 19 & 43 & \\
\hline$>54$ & 23 & 30 & \\
\hline FIGO stage & & & $0.756^{\mathrm{b}}$ \\
\hline I-II & 5 & 7 & \\
\hline III-IV & 37 & 66 & \\
\hline Histological grade & & & $1.000^{\mathrm{b}}$ \\
\hline $\mathrm{G} 2$ & 5 & 9 & \\
\hline G3 & 34 & 63 & \\
\hline Null & 3 & 1 & \\
\hline $\mathrm{CA}-125, \mathrm{U} / \mathrm{ml}$ & & & $0.078^{\mathrm{a}}$ \\
\hline$\leq 500$ & 6 & 21 & \\
\hline$>500$ & 36 & 52 & \\
\hline Lymph node metastasis & & & $0.884^{\mathrm{a}}$ \\
\hline No & 19 & 32 & \\
\hline Yes & 23 & 41 & \\
\hline Residual tumor size, $\mathrm{cm}$ & & & $0.547^{\mathrm{a}}$ \\
\hline$\leq 1$ & 31 & 50 & \\
\hline$>1$ & 11 & 23 & \\
\hline Platinum resistance & & & $0.001^{\mathrm{b}}$ \\
\hline Present & 2 & 22 & \\
\hline Absent & 39 & 47 & \\
\hline Null & 1 & 4 & \\
\hline
\end{tabular}

Statistical analysis was performed with a ${ }^{a} \chi^{2}$ test or ${ }^{b}$ Fisher's exact test. The information of some individuals was missing or incomplete, therefore the total number is inconsistent. MBD2 methyl-CpG binding domain protein 2; FIGO, International Federation of Gynaecology and Obstetrics; CA-125, cancer antigen-125; Null, missing/unavailable data.

eight normal ovarian tissues. The results demonstrated that the expression of MBD2 was significantly higher in HGSOC tissues compared with that in normal tissues (Fig. 3).
Table III. Associations between chemotherapy resistance and clinicopathological characteristics.

\begin{tabular}{|c|c|c|c|}
\hline \multirow[b]{2}{*}{ Variable } & \multicolumn{3}{|c|}{ Platinum resistance } \\
\hline & Present & Absent & P-value \\
\hline Age, years & & & $0.806^{\mathrm{a}}$ \\
\hline$\leq 54$ & 13 & 49 & \\
\hline$>54$ & 11 & 37 & \\
\hline FIGO stage & & & $0.065^{\mathrm{b}}$ \\
\hline I-II & 0 & 12 & \\
\hline III-IV & 24 & 74 & \\
\hline Histological grade & & & $0.498^{\mathrm{b}}$ \\
\hline $\mathrm{G} 2$ & 4 & 10 & \\
\hline G3 & 19 & 73 & \\
\hline Null & 1 & 3 & \\
\hline $\mathrm{CA}-125, \mathrm{U} / \mathrm{ml}$ & & & $0.710^{\mathrm{b}}$ \\
\hline$\leq 500$ & 5 & 21 & \\
\hline$>500$ & 19 & 65 & \\
\hline Lymph node metastasis & & & $0.106^{\mathrm{a}}$ \\
\hline No & 7 & 41 & \\
\hline Yes & 17 & 45 & \\
\hline Residual tumor size & & & $0.030^{\mathrm{a}}$ \\
\hline$\leq 1 \mathrm{~cm}$ & 13 & 66 & \\
\hline$>1 \mathrm{~cm}$ & 11 & 20 & \\
\hline MBD2 expression & & & $0.001^{\mathrm{b}}$ \\
\hline Low & 2 & 39 & \\
\hline High & 22 & 47 & \\
\hline
\end{tabular}

Statistical analysis was performed with a ${ }^{a} \chi^{2}$ test or ${ }^{b}$ Fisher's exact test. The information of some individuals was missing or incomplete, therefore the total number is inconsistent. FIGO, International Federation of Gynaecology and Obstetrics; MBD2 methyl-CpG binding domain protein 2; CA-125, cancer antigen-125; Null, missing/unavailable data.

Associations between platinum resistance and clinicopathological characteristics of patients with HGSOC. It was demonstrated that postoperative residual tumor size $(\mathrm{P}=0.030)$ and MBD2 expression $(\mathrm{P}=0.001)$ were significantly associated with platinum resistance. However, platinum resistance was not associated with age, FIGO stage, histological grade, CA-125 or lymph node metastasis $(\mathrm{P}>0.05$; Table III). Multivariate logistic regression analysis confirmed that $>1 \mathrm{~cm}$ of residual disease and high expression of MBD2 were significantly associated with platinum resistance $(\mathrm{P}<0.05$; Table IV).

Prognostic value of MBD2 expression in ovarian cancer. Kaplan-Meier univariate analysis demonstrated that MBD2 expression, FIGO stage, CA-125, lymph node metastasis and residual tumor size were significantly associated with relapse-free survival (RFS) in patients with HGSOC $(\mathrm{P}<0.05$; Table V). Multivariate Cox regression analysis demonstrated that FIGO stage, CA-125, lymph node metastasis, residual tumor size and MBD2 expression were significantly associated with RFS $(\mathrm{P}<0.05$; Table VI). Therefore, late FIGO, CA-125 
Table IV. Multivariate logistic analysis of the association between chemotherapy resistance and clinicopathological characteristics

\begin{tabular}{lccccr}
\hline Variable & $\beta$ & SE & $\operatorname{Exp}(\beta)$ & $95 \%$ CI & P-value \\
\hline Residual tumor $(>1 \mathrm{~cm})$ & -1.028 & 0.515 & 0.358 & $0.130-0.981$ & $0.046^{\mathrm{a}}$ \\
MBD2 expression $(\mathrm{High})$ & -2.212 & 0.777 & 0.109 & $0.024-0.502$ & $0.004^{\mathrm{b}}$ \\
\hline
\end{tabular}

${ }^{\mathrm{a}} \mathrm{P}<0.05,{ }^{\mathrm{b}} \mathrm{P}<0.01$. MBD2 methyl-CpG binding domain protein 2; SE, standard error; CI, confidence interval.

A

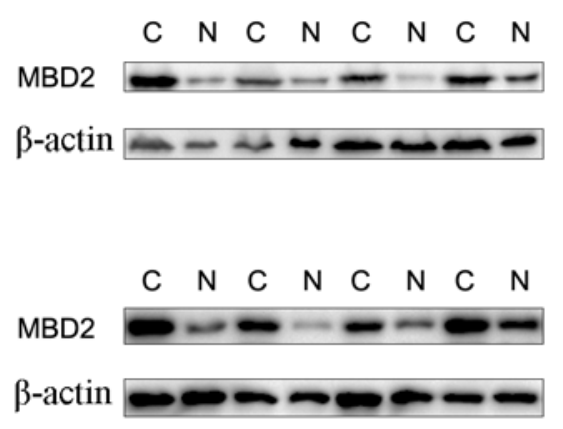

B

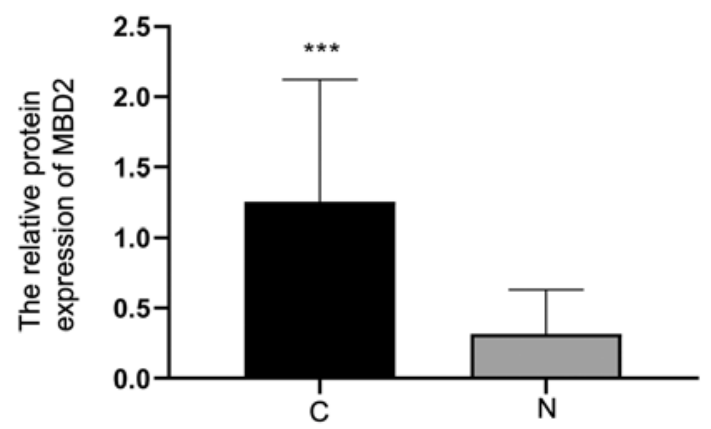

Figure 3. Detection of MBD2 using western blotting. (A) Representative western blots and (B) analysis demonstrating that MBD2 expression was higher in HGSOC tissues compared with that in normal tissues. ${ }^{* * *} \mathrm{P}<0.001$. MBD2, methyl-CpG binding domain protein 2 ; $\mathrm{C}$, ovarian cancer tissue; $\mathrm{N}$, normal ovarian tissue.

$>500$, lymph node metastasis, $>1 \mathrm{~cm}$ of postoperative residual disease and high expression of MBD2 were identified as risk factors for recurrence of HGSOC.

\section{Discussion}

MBD2 is closely associated with the hypermethylation of $\mathrm{CpG}$ islands in some cancer types, such as breast and prostate cancer $(9,30)$. And it has been reported to function as a tumor activator $(31,32)$. Knockout of MBD2 upregulates the expression of tumor suppressor genes, such as p16 and p14 $(33,34)$. MBD2 overexpression has been detected in a variety of solid tumors, including HCC, breast cancer, GBM and chronic myeloid leukemia (16-18,35). MBD2 promotes breast cancer progression by mediating tumor suppressor gene silencing $(22,36)$. Zhu et al (16) reported that MBD2 overexpression leads to silencing of cerebral angiogenesis inhibitor 1 to promote the growth of GBM. Similar mechanisms have been reported in other cancers, such as HCC and gastrointestinal stromal tumors (17,37). However, MBD2 functions in a celland tissue-specific manner, and recent studies demonstrated that MBD2 has antitumor effects $(21,38)$. MBD2 is downregulated in lung adenocarcinoma, and low expression of MBD2 is associated with poor prognosis (38). In vitro experiments further demonstrated that MBD2 inhibits metastasis (38). The results of the present study demonstrated that MBD2 was expressed at high levels in HGSOC, although the underlying mechanism remains unclear.

Approximately $20-30 \%$ of patients with ovarian cancer develop platinum resistance during chemotherapy (39). In the current study, $21.8 \%$ of patients developed platinum resistance, which is consistent with a recent study (39). Huang et al (40) performed a transcriptome analysis of platinum-sensitive and drug-resistant ovarian cancer cell lines and found differences in the expression of MBD2 between the two populations. $\mathrm{Yu}$ et al (41) used methyl-capture sequencing to precipitate methylated DNA from the recombinant methyl CpG binding domain of MBD2 for next generation sequencing. The results demonstrated that drug-resistant cells had lower levels of $\mathrm{CpG}$ methylation. The results of the present study revealed that MBD2 upregulation was related to platinum resistance in HGSOC, although the underlying mechanism needs to be further studied.

The results of the present study suggested that the recurrence of HGSOC was associated with numerous factors, such as late FIGO stage, lymph node metastasis and high expression of MBD2. The postoperative recurrence of epithelial ovarian cancer is related to clinical stage (42). The results of the present study demonstrated that postoperative recurrence of HGSOC was significantly correlated with advanced FIGO stage, which was consistent with a previous report (43). A higher tumor stage was associated with larger tumors, which may lead to local invasion. Surgical excision in these cases is difficult and may lead to injury, which increases the potential for cancer cells to invade blood vessels and lymphoid tissues, increases the depth of infiltration and promotes tumor metastasis $(44,45)$. The present study also demonstrated that lymph node metastasis was a risk factor for recurrence of HGSOC, which was consistent with a previous study (46). One possible reason for this finding is that lymph node metastasis 
Table V. Univariate survival analysis of relapse-free survival of patients with ovarian cancer.

\begin{tabular}{|c|c|c|c|c|}
\hline Variable & $\mathrm{n}$ & Mean \pm SE & $95 \% \mathrm{CI}$ & P-value \\
\hline Age, years & & & & $0.978^{\mathrm{b}}$ \\
\hline$\leq 54$ & 62 & $21.760 \pm 3.049$ & $15.783-27.737$ & \\
\hline$>54$ & 48 & $24.375 \pm 3.607$ & $17.306-31.444$ & \\
\hline FIGO stage & & & & $<0.001^{\mathrm{a}}$ \\
\hline I-II & 12 & $67.917 \pm 9.288$ & $49.712-86.121$ & \\
\hline III-IV & 98 & $17.991 \pm 1.859$ & $14.347-21.635$ & \\
\hline Histological grade & & & & $0.488^{\mathrm{a}}$ \\
\hline $\mathrm{G} 2$ & 14 & $20.643 \pm 5.808$ & $9.260-32.026$ & \\
\hline G3 & 92 & $24.140 \pm 2.725$ & $18.799-29.480$ & \\
\hline Null & 4 & & & \\
\hline $\mathrm{CA}-125, \mathrm{U} / \mathrm{ml}$ & & & & $0.022^{\mathrm{a}}$ \\
\hline 500 & 26 & $32.138 \pm 5.746$ & $20.877-43.400$ & \\
\hline$>500$ & 84 & $19.698 \pm 2.306$ & $15.179-24.217$ & \\
\hline Lymph node metastasis & & & & $<0.001^{\mathrm{a}}$ \\
\hline No & 48 & $33.089 \pm 4.547$ & $24.177-42.001$ & \\
\hline Yes & 62 & $15.414 \pm 1.888$ & $11.713-19.115$ & \\
\hline Residual tumor size, $\mathrm{cm}$ & & & & $0.002^{\mathrm{a}}$ \\
\hline$\leq 1$ & 79 & $27.309 \pm 3.163$ & 21.109-33.508 & \\
\hline$>1$ & 31 & $13.645 \pm 2.664$ & $8.423-18.867$ & \\
\hline MBD2 expression & & & & $0.011^{\mathrm{b}}$ \\
\hline Low & 41 & $28.786 \pm 4.221$ & 20.514-37.059 & \\
\hline High & 69 & $18.662 \pm 2.408$ & $13.942-23.381$ & \\
\hline
\end{tabular}

Analysis was performed with a ${ }^{\mathrm{a}} \log$-rank test or ${ }^{\mathrm{b}}$ Breslow test. The information of some individuals was missing or incomplete, therefore the total number is inconsistent. MBD2 methyl-CpG binding domain protein 2; CA-125, cancer antigen-125; SE, standard error; CI, confidence interval; Null, missing/unavailable data.

Table VI. Multivariate survival analysis of relapse-free survival of patients with ovarian cancer.

\begin{tabular}{lccccr}
\hline Variable & $\beta$ & SE & HR & 95\% CI & P-value $^{\mathrm{a}}$ \\
\hline FIGO stage (III-IV) & 1.786 & 0.618 & 5.965 & $1.776-20.041$ & 0.004 \\
CA-125 (>500) & 0.678 & 0.281 & 1.971 & $1.135-3.421$ & 0.016 \\
Lymph node metastasis (Yes) & 0.450 & 0.227 & 1.568 & $1.004-2.448$ & 0.048 \\
Residual tumor size (>1 cm) & 0.477 & 0.234 & 1.610 & $1.017-2.549$ & 0.042 \\
MBD2 expression (High) & 0.525 & 0.222 & 1.691 & $1.093-2.615$ & 0.018 \\
\hline
\end{tabular}

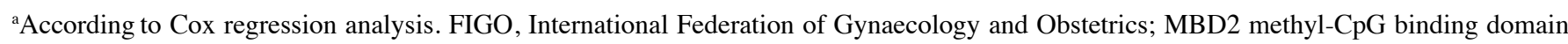
protein 2; CA-125, cancer antigen-125; SE, standard error; CI, confidence interval; HR, hazard ratio.

is the most common type of ovarian cancer metastasis, which also increases the risk of recurrence $(47,48)$. The results of the present study demonstrated that a postoperative residual tumor size $\leq 1 \mathrm{~cm}$ prevented postoperative recurrence, which was consistent with previous reports $(49,50)$. Therefore, maximum radical resection of the tumor and reduction of residual cancer tissue are essential to improve the prognosis of HGSOC. In addition, the expression level of MBD2 in HCC is higher compared with that in normal tissues (51). MBD2 is an independent prognostic factor that affects the overall survival and disease-free survival of patients and is considered to be a potential clinical prognostic marker (17). Notably, the current study also identified MBD2 as an independent prognostic factor for relapse-free survival of HGSOC.

To the best of our knowledge, the present study is the first to demonstrate that high expression levels of MBD2 are associated with platinum resistance and poor prognosis in patients with HGSOC. The results suggested that MBD2 is a promising target for cancer treatment. Sequence-specific antisense MBD2 inhibitors suppress the anchorage-independent 
growth of human tumor cell lines in vitro and the growth of human tumor xenografts in vivo (52). The newly discovered MBD2 inhibitor KCC-08 combined with the retinoic acid receptor agonist isoretinoic acid can significantly reduce the growth and survival of cancer cells (53). However, the present study had some limitations, such as a small sample size and the nature of the study as a single-center study. In conclusion, patients with HGSOC with high MBD2 expression levels are more likely to develop platinum resistance and have a poor prognosis; thus MBD2 is a potential biomarker for HGSOC.

\section{Acknowledgements}

Not applicable.

\section{Funding}

This study was financially supported by the Natural Science Foundation of Zhejiang Province (grant no. LY19H160003) and the Medical Health Science and Technology Project of Zhejiang Province (grant no. 2018KY294).

\section{Availability of data and materials}

The datasets used and/or analyzed during the current study are available from the corresponding author on reasonable request.

\section{Authors' contributions}

WG wrote the paper and performed the experiments. MN and $\mathrm{ZC}$ participated in the data collection and analysis. $\mathrm{ZZ}$ conceived and designed the study. All authors read and approved the final manuscript.

\section{Ethics approval and consent to participate}

The study was approved by the Ethics Committee of Zhejiang Cancer Hospital (approval no. IRB-2015-175) and written informed consent was obtained from all patients.

\section{Patient consent for publication}

Not applicable.

\section{Competing interests}

The authors declare that they have no competing interests.

\section{References}

1. Global Burden of Disease Cancer Collaboration, Fitzmaurice C, Dicker D, Pain A, Hamavid H, Moradi-Lakeh M, MacIntyre MF, Allen C, Hansen G, Woodbrook R, et al: The global burden of cancer 2013. JAMA Oncol 1: 505-527, 2015.

2. Siegel RL, Miller KD and Jemal A: Cancer statistics, 2018. CA Cancer J Clin 68: 7-30, 2018.

3. Colombo PE, Fabbro M, Theillet C, Bibeau F, Rouanet P and Ray-Coquard I: Sensitivity and resistance to treatment in the primary management of epithelial ovarian cancer. Crit Rev Oncol Hematol 89: 207-216, 2014.

4. Lheureux S, Braunstein M and Oza AM: Epithelial ovarian cancer: Evolution of management in the era of precision medicine. CA Cancer J Clin 69: 280-304, 2019.
5. Wallace S, Kumar A, Mc Gree M, Weaver A, Mariani A, Langstraat C, Dowdy S, Bakkum-Gamez J and Cliby W: Efforts at maximal cytoreduction improve survival in ovarian cancer patients, even when complete gross resection is not feasible. Gynecol Oncol 145: 21-26, 2017.

6. Li YC, Wang Y, Li DD, Zhang Y, Zhao TC and Li CF: Procaine is a specific DNA methylation inhibitor with anti-tumor effect for human gastric cancer. J Cell Biochem 119: 2440-2449, 2018.

7. Parry L and Clarke AR: The roles of the methyl-CpG binding proteins in cancer. Genes Cancer 2: 618-630, 2011.

8. Defossez PA and Stancheva I: Biological functions of methyl-CpG-binding proteins. Prog Mol Biol Transl Sci 101: 377-398, 2011

9. Stirzaker C, Song JZ, Ng W, Du Q, Armstrong NJ, Locke WJ, Statham AL, French H, Pidsley R, Valdes-Mora F, et al: Methyl-CpG-binding protein MBD2 plays a key role in maintenance and spread of DNA methylation at $\mathrm{CpG}$ islands and shores in cancer. Oncogene 36: 1328-1338, 2017.

10. Du Q, Luu PL, Stirzaker C and Clark SJ: Methyl-CpG-binding domain proteins: Readers of the epigenome. Epigenomics 7: 1051-1073, 2015

11. Lai AY and Wade PA: Cancer biology and NuRD: A multifaceted chromatin remodelling complex. Nat Rev Cancer 11: 588-596, 2011.

12. Ramirez J, Dege C, Kutateladze TG and Hagman J: MBD2 and multiple domains of CHD4 are required for transcriptional repression by $\mathrm{Mi}-2 / \mathrm{NuRD}$ complexes. Mol Cell Biol 32: 5078-5088, 2012.

13. Cai Y, Geutjes EJ, de Lint K, Roepman P, Bruurs L, Yu LR, Wang W, van Blijswijk J, Mohammad H, de Rink I, et al: The NuRD complex cooperates with DNMTs to maintain silencing of key colorectal tumor suppressor genes. Oncogene 33: 2157-2168, 2014.

14. Tan CP and Nakielny S: Control of the DNA methylation system component MBD2 by protein arginine methylation. Mol Cell Biol 26: 7224-7235, 2006.

15. Fujita H, Fujii R, Aratani S, Amano T, Fukamizu A and Nakajima T: Antithetic effects of MBD2a on gene regulation. Mol Cell Biol 23: 2645-2657, 2003.

16. Zhu D, Hunter SB, Vertino PM and Van Meir EG: Overexpression of MBD2 in glioblastoma maintains epigenetic silencing and inhibits the antiangiogenic function of the tumor suppressor gene BAI1. Cancer Res 71: 5859-5870, 2011.

17. Pan ZX, Zhang XY, Chen SR and Li CZ: Upregulated exosomal miR-221/222 promotes cervical cancer via repressing methyl-CpG-binding domain protein 2. Eur Rev Med Pharmacol Sci 23: 3645-3653, 2019.

18. Izquierdo-Torres E, Hernández-Oliveras A, Meneses-Morales I, Rodríguez G, Fuentes-García G and Zarain-Herzberg Á: Resveratrol up-regulates ATP2A3 gene expression in breast cancer cell lines through epigenetic mechanisms. Int J Biochem Cell Biol 113: 37-47, 2019.

19. Pontes TB, ChenES, Gigek CO,Calcagno DQ, WisnieskiF,Leal MF, Demachki S, Assumpção PP, Artigiani R, Lourenco LG, et al: Reduced mRNA expression levels of MBD2 and MBD3 in gastric carcinogenesis. Tumour Biol 35: 3447-3453, 2014.

20. May S, Owen H,Phesse TJ, Greenow KR, Jones GR, Blackwood A, Cook PC, Towers C, Gallimore AM, Williams GT, et al: Mbd2 enables tumourigenesis within the intestine while preventing tumour-promoting inflammation. J Pathol 245: 270-282, 2018.

21. Liu W, Wang N, Lu M, Du XJ and Xing BC: MBD2 as a novel marker associated with poor survival of patients with hepatocellular carcinoma after hepatic resection. Mol Med Rep 14: 1617-1623, 2016.

22. Mian OY, Wang SZ, Zhu SZ, Gnanapragasam MN, Graham L, Bear HD and Ginder GD: Methyl-binding domain protein 2-dependent proliferation and survival of breast cancer cells. Mol Cancer Res 9: 1152-1162, 2011.

23. Yuan K, Xie K, Fox J, Zeng H, Gao H, Huang C and Wu M: Decreased levels of miR-224 and the passenger strand of miR-221 increase MBD2, suppressing maspin and promoting colorectal tumor growth and metastasis in mice. Gastroenterology 145 : 853-864 e9, 2013.

24. Thul PJ and Lindskog C: The human protein atlas: A spatial map of the human proteome. Protein Sci 27: 233-244, 2018.

25. Uhlén M, Fagerberg L, Hallström BM, Lindskog C, Oksvold P, Mardinoglu A, Sivertsson Å, Kampf C, Sjöstedt E, Asplund A, et al: Proteomics. Tissue-based map of the human proteome. Science 347: 1260419, 2015.

26. Thul PJ, Åkesson L, Wiking M, Mahdessian D, Geladaki A, Ait Blal H, Alm T, Asplund A, Björk L, Breckels LM, et al: A subcellular map of the human proteome. Science 356 : eaal3321, 2017. 
27. Uhlen M, Zhang C, Lee S, Sjöstedt E, Fagerberg L, Bidkhori G, Benfeitas R, Arif M, Liu Z, Edfors F, et al: A pathology atlas of the human cancer transcriptome. Science 357: eaan2507, 2017.

28. Zeppernick F and Meinhold-Heerlein I: The new FIGO staging system for ovarian, fallopian tube, and primary peritoneal cancer. Arch Gynecol Obstet 290: 839-842, 2014.

29. Zhang M, Liu T, Xia B, Yang C, Hou S, Xie W and Lou G: Platelet-derived growth factor $\mathrm{D}$ is a prognostic biomarker and is associated with platinum resistance in epithelial ovarian cancer. Int J Gynecol Cancer 28: 323-331, 2018.

30. Devailly G, Grandin M, Perriaud L, Mathot P, Delcros JG, Bidet Y, Morel AP, Bignon JY, Puisieux A, Mehlen P and Dante R: Dynamics of MBD2 deposition across methylated DNA regions during malignant transformation of human mammary epithelial cells. Nucleic Acids Res 43: 5838-5854, 2015.

31. Wood KH and Zhou Z: Emerging molecular and biological functions of MBD2, a reader of DNA methylation. Front Genet 7: 93, 2016.

32. Mahmood N and Rabbani SA: DNA methylation readers and cancer: Mechanistic and therapeutic applications. Front Oncol 9: 489, 2019.

33. Le Guezennec $X$, Vermeulen M, Brinkman AB, Hoeijmakers WA, Cohen A, Lasonder E and Stunnenberg HG: MBD2/NuRD and MBD3/NuRD, two distinct complexes with different biochemical and functional properties. Mol Cell Biol 26: 843-851, 2006.

34. Magdinier F and Wolffe AP: Selective association of the methyl-CpG binding protein MBD2 with the silent p14/p16 locus in human neoplasia. Proc Natl Acad Sci USA 98: 4990-4995, 2001.

35. Cheng L, Tang Y, Chen X, Zhao L, Liu S, Ma Y, Wang N, Zhou K, Zhou J and Zhou M: Deletion of MBD2 inhibits proliferation of chronic myeloid leukaemia blast phase cells. Cancer Biol Ther 19: 676-686, 2018.

36. Alvarado S, Wyglinski J, Suderman M, Andrews SA and Szyf M: Methylated DNA binding domain protein 2 (MBD2) coordinately silences gene expression through activation of the microRNA hsa-mir-496 promoter in breast cancer cell line. PLoS One 8: e74009, 2013.

37. He M, Fan J, Jiang R, Tang WX and Wang ZW: Expression of DNMTs and MBD2 in GIST. Biomed Rep 1: 223-227, 2013.

38. Pei YF, Xu XN, Wang ZF, Wang FW, Wu WD, Geng JF and Liu XQ: Methyl-CpG binding domain protein 2 inhibits the malignant characteristic of lung adenocarcinoma through the epigenetic modulation of 10 to 11 translocation 1 and miR-200s Am J Pathol 189: 1065-1076, 2019.

39. Berns EM and Bowtell DD: The changing view of high-grade serous ovarian cancer. Cancer Res 72: 2701-2704, 2012.

40. Huang RL, Gu F, Kirma NB, Ruan J, Chen CL, Wang HC, Liao YP, Chang CC, Yu MH, Pilrose JM, et al: Comprehensive methylome analysis of ovarian tumors reveals hedgehog signaling pathway regulators as prognostic DNA methylation biomarkers. Epigenetics 8: 624-634, 2013 .

41. Yu W, Jin C, Lou X, Han X, Li L, He Y, Zhang H, Ma K, Zhu J, Cheng L and Lin B: Global analysis of DNA methylation by Methyl-Capture sequencing reveals epigenetic control of cisplatin resistance in ovarian cancer cell. PLoS One 6: e29450, 2011.
42. Kehoe S, Hook J, Nankivell M, Jayson GC, Kitchener H, Lopes T, Luesley D, Perren T, Bannoo S, Mascarenhas M, et al: Primary chemotherapy versus primary surgery for newly diagnosed advanced ovarian cancer (CHORUS): An open-label, randomised, controlled, non-inferiority trial. Lancet 386: 249-257, 2015.

43. Tsuyoshi H, Orisaka M, Fujita Y, Asare-Werehene M, Tsang BK and Yoshida Y: Prognostic impact of dynamin related protein 1 (Drp1) in epithelial ovarian cancer. BMC Cancer 20: 467, 2020.

44. Mirza MR, Monk BJ, Herrstedt J, Oza AM, Mahner S, Redondo A, Fabbro M, Ledermann JA, Lorusso D, Vergote I, et al: Niraparib maintenance therapy in platinum-sensitive, recurrent ovarian cancer. N Engl J Med 375: 2154-2164, 2016.

45. Ducie J, Dao F, Considine M, Olvera N, Shaw PA, Kurman RJ, Shih IM, Soslow RA, Cope L and Levine DA: Molecular analysis of high-grade serous ovarian carcinoma with and without associated serous tubal intra-epithelial carcinoma. Nat Commun 8: 990, 2017

46. Joueidi Y, Dion L, Bendifallah S, Mimoun C, Bricou A, Nyangoh Timoh K, Collinet P, Touboul C, Ouldamer L, Azaïs H, et al: Management and survival of elderly and very elderly patients with ovarian cancer: An age-stratified study of 1123 women from the FRANCOGYN group. J Clin Med 9: 1451, 2020.

47. Scott LJ: Niraparib: First global approval. Drugs 77: 1029-1034, 2017.

48. Lorusso D, Scambia G, Pignata S, Sorio R, Amadio G, Lepori S, Mosconi A, Pisano C, Mangili G, Maltese G, et al: Prospective phase II trial of trabectedin in BRCA-mutated and/or BRCAness phenotype recurrent ovarian cancer patients: The MITO 15 trial. Ann Oncol 27: 487-493, 2016.

49. Fan XM, Zhang J, Niu SH, Li KX and Song CZ: Secondary cytoreductive surgery in recurrent epithelial ovarian cancer: A prognostic analysis with 103 cases. Int J Surg 38: 61-66, 2017.

50. du Bois A, Reuss A, Pujade-Lauraine E, Harter P, Ray-Coquard I and Pfisterer J: Role of surgical outcome as prognostic factor in advanced epithelial ovarian cancer: A combined exploratory analysis of 3 prospectively randomized phase 3 multicenter trials: By the arbeitsgemeinschaft gynaekologische onkologie studiengruppe ovarialkarzinom (AGO-OVAR) and the groupe d'Investigateurs nationaux pour les etudes des cancers de l'Ovaire (GINECO). Cancer 115: 1234-1244, 2009.

51. E C, Li C, Li H and Yang J: Silencing of a novel lncRNA LOC105369748 suppresses the progression of hepatocellular carcinoma by sponging miR-5095 from MBD2. J Cell Physiol 234: 18504-18512, 2019.

52. Campbell PM, Bovenzi V and Szyf M: Methylated DNA-binding protein 2 antisense inhibitors suppress tumourigenesis of human cancer cell lines in vitro and in vivo. Carcinogenesis 25: 499-507, 2004.

53. Giovinazzo H, Reichert ZR, Bergman A, Lin X, Wyhs N, Esopi D, Vaghasia A, Liu J, Jain Y, Bhamidipati A, et al: Abstract 5881: Novel inhibitors of the epigenetic reader protein MBD2. Cancer Res 78 (Suppl 13): S5881, 2018.

This work is licensed under a Creative Commons Attribution-NonCommercial-NoDerivatives 4.0 International (CC BY-NC-ND 4.0) License. 